\title{
Paideusis
}

\section{The Character of Moral Development}

\section{Dwight Boyd}

Volume 2, Number 2, 1989

URI: https://id.erudit.org/iderudit/1073416ar

DOI: https://doi.org/10.7202/1073416ar

See table of contents

Publisher(s)

Canadian Philosophy of Education Society

ISSN

0838-4517 (print)

1916-0348 (digital)

Explore this journal

Cite this article

Boyd, D. (1989). The Character of Moral Development. Paideusis, 2(2), 21-48. https://doi.org/10.7202/1073416ar
Article abstract

This paper analyzes the character implications of Kohlberg's conception of moral development combined with our current understanding of the moral point of view inherent in the most mature level of that development. The problem is first framed within an articulation of the most fundamental philosophical assumptions underlying Kohlberg's theory. Then the argument proceeds dialectically from correcting some of the common but mistaken character implications of the notion of principled morality to showing what positive picture of moral character emerges from an appreciation of recent elaborations of the nature of Stage Six. It is argued that certain dimensions of moral character are required by the performative sense of objectivity which operationalizes the notion of respect for persons forming the heart of Stage Six.
This document is protected by copyright law. Use of the services of Erudit (including reproduction) is subject to its terms and conditions, which can be viewed online.

https://apropos.erudit.org/en/users/policy-on-use/ 


\title{
The Character of Moral Development ${ }^{1}$
}

\author{
Dwight Boyd, Department of History and Philosophy \\ The Ontario Institute for Studies in Education
}

\begin{abstract}
This paper analyzes the character implications of Kohlberg's conception of moral development combined with our current understanding of the moral point of view inherent in the most mature level of that development. The problem is first framed within an articulation of the most fundamental philosophical assumptions underlying Kohlberg's theory. Then the argument proceeds dialectically from correcting some of the common but mistaken character implications of the notion of principled morality to showing what positive picture of moral character emerges from an appreciation of recent elaborations of the nature of Stage Six. It is argued that certain dimensions of moral character are required by the performative sense of objectivity which operationalizes the notion of respect for persons forming the heart of Stage Six.
\end{abstract}

\section{Introduction}

One of the criticisms that has often been levelled at Lawrence Kohlberg's conception of moral development is that it manifests an impoverished, even warped, view of human persons. Forms of this criticism can be found, either asserted or implied, in intellectuallyrespectable critiques published by a number of our colleagues 2 and in the blatantly rhetorical and not so intellectually respectable papers of U.S. Secretary of Education William Bennett. ${ }^{3}$ What motivates this paper is the belief that, although there is an important concern underlying this criticism, at least a good part of how it is developed is mistaken. What can be taken from the criticism is an encouragement to think more directly and explicitly about how matters of character interact with the theory of moral development as currently expressed in the writings of Kohlberg and his colleagues. On the other hand, the mistake which seems to me quite common is to misinterpret certain aspects of the theory in such a way as to create a straw-person, the character of which can then be dismissively caricatured (and along with it, the theory as a whole).

In this paper $I$ will endeavour to articulate a more adequate understanding of Kohlberg's theory, with respect to which the strawperson nature of some lines of criticism can be more clearly seen, and 
within which some positive claims about character can be illuminated as an integral part of the theory. In order to do this, I will cover several different kinds of ground. After a more focused statement of the problem, it will be necessary first to synthesize what seem to me to be some of the most fundamental philosophical assumptions underlying Kohlberg's theory which the aforementioned criticisms often lose sight of, but which must be kept clearly in mind for any full picture of the character of moral development. Then I will work dialectically from correcting some of the common, but mistaken, character implications of the notion of principled morality to showing what positive picture of character emerges from an appreciation of recent elaborations of the nature of stage six, in the context of the philosophical assumptions already identified. Finally, in order to accomplish the positive task I will argue that this more adequate interpretation hinges on an understanding of objectivity in morality different from that commonly assumed.

\section{The Problem Refined}

On the basis of a unique blend of philosophical reflection and empirical study, Kohlberg sought to describe moral learning over the lifespan in developmental terms. As the notion of "development" carries with it not only the notion of change but also change with regard to some specified dimension and in some direction considered to be an improvement, he also needed to articulate his conception of the aim of that development. Kohlberg understood that one's conception of the endpoint of a hierarchically related sequence of developmental stages serves both to draw boundaries around what is to be counted as falling within the domain of this empirical study and to establish criteria by which one can order the data so found into increasing steps of greater adequacy. In addressing this aspect of his theory, Kohlberg repeatedly described a post-conventional level of moral reasoning and, more specifically, a "stage six" within that level, in terms of the notion of a principled interpretation of justice as respect for persons. This has been spelled out in a variety of ways, but a good example for my purposes is the following. Stage six is described as:

The universal-ethical-principle orientation. Right is defined by the decision of conscience in accord with self-chosen ethical principles appealing to logical comprehensiveness, universality, and consistency. These principles are abstract and ethical (the Golden Rule, the categorical imperative); they are not concrete moral rules like the Ten Commandments. At heart, these are universal principles of justice, of the reciprocity and equality of human rights, and of 
respect for the dignity of human beings as individual persons. 4

A communicative problem arises here: such short content descriptions of complex structures of judgment can be extremely misleading. To put it in terms of an analogy, such descriptions in terms of content are like the small, usually dirty windows on the landings of staircases through which, if you are on the outside of the building and lucky, you can sometimes get a vague glimpse of people and the direction they are walking on the staircase. Despite Kohlberg's several efforts to articulate the form of stage six more fully, some critics have taken certain aspects of such short content descriptions as constituting an accurate picture of stage six. The problem is, however, that these aspects are taken out of the context of a full understanding of the theory as a whole and the structure of stage six within it. The result is a severely warped, attenuated picture. Moreover, what is important in this paper is that what gets warped and attenuated is not only stage six as a form of moral judgment, but also, through an oddly intellectualized process of guilt-byassociation, the person who might find such a form of moral judgment accommodating. By correcting these misinterpretations of stage six, we can lay the groundwork for a more balanced and plausible understanding of the character of moral development implicit in Kohlberg's theory.

Before the main analysis and argument can proceed, two further refinements are necessary to clarify the nature of the task. Both involve additional problems of communication not inherent in Kohlberg's writings but in the way the notion of character is being used in this paper. The first is an acknowledgement of the intentional ambiguity in the title phrase, "the character of moral development." I intend to work from the "character of moral development" in the sense of the understanding we currently have about the nature of moral development and the direction it takes (according to Kohlberg's theory) to an articulation of the "character of moral development" in the sense of what we might then want to say about the moral character of a person, fully developed according to this view. A short-hand way of saying this is in terms of the question "what moral aspects of the person, of character, would seem best to 'fit' our current understanding of stage six in Kohlberg's theory?"

Having put the question in this way, I want to finesse the concern that might reasonably then be raised about the nature of this project--viz., what kind of 'fit' am I presupposing and seeking to uncover? The stages of moral development, as conceived by Kohlberg, are clearly not descriptions of types of persons; nor should they ever 
be thought of in this way. They are, instead, qualitatively different patterns of interpreting and resolving particular aspects of social interaction among human persons. They are descriptions of a psychological function which persons engage in, not descriptions of the moral persons themselves. It is, then, conceptually confused, and in some contexts morally pernicious, to speak in terms such as "the stage two person," or "the stage six person." Thus, I want to reject any interpretation of my project as simply translating stage descriptions into character talk. On the contrary, this move must be framed more hypothetically, indeed, more speculatively. The question is better understood as follows: if a person had the capacity for stage six moral judgment, and were to be conceived as using that capacity to interpret and seek resolution of moral problems, given our current understanding of stage six, what character traits would be seen as congruent with and as facilitating this capacity and/or use? I realize, of course, that this approach walks immediately into a barrage of conceptual questions having to do with the difference between having a capacity and using that capacity, and this distinction must, in the end, be taken seriously in any thorough consideration of mature moral character. Moreover, there are also quite number of other empirical questions about the relationship between moral development in terms of stages of moral judgment and in terms of the manifestation of a set of (approved) character traits. I want to acknowledge that these are all crucial questions for us to explore. However, I think now we are necessarily at a much grosser level. What we need first, I believe, is a theoretically sound and plausible picture of the categories of concern in terms of which such further exploration could be approached.

The final refinement consists of a need to avoid vagueness in subsequent use of the term "character." To what do I take the notion of moral character to be referring? This is not a notion that has received much attention within mainstream moral development theory ever since Kohlberg ${ }^{5}$ excoriated it with the label "bag of virtues." Of course, some critics of this rejection have repeatedly argued that one cannot get rid of it so easily (e.g. Peters ${ }^{6}$ and Hamm ${ }^{7}$ ), and it may even be sneaking back into favour in current developmentalist work on the notion of "the moral self." But it is clear that the notion itself is not very clear. Much of the argument and counter-argument hinges, I suspect, on different understandings of what character encompasses. In order to avoid adding to these problems of interpretation, but without getting into an elaborate conceptual analysis, I will simply assert here as concisely and precisely as possible the outlines of the concept of moral character I will be using. 
In short, I will use "moral character" to mean those enduring aspects of the expression of personhood to which we are inclined to give moral evaluation across different attitudinal and behavioural contexts. There are several components of this understanding that need emphasizing. (1) Character is the way we express our being as persons via attitudinal and behavioural dispositions. (2) These expressions are not just episodic, but must be relatively consistent over time. That is why we often refer to character traits. (3) From the standpoint of the other, they raise dependable expectations with regard to the person, regardless of what particular behaviour is evidenced - even regardless of whether this particular behaviour is a successful expression of the intended aspect of character. (Note that ' 2 ' and ' 3 ' together allow us to speak of "strong" or "weak" characters.) (4) Some expressions will be non-moral character traits; others will be clearly moral; and it is possible for some to be both, depending on context. What will determine whether or not something is an instance of moral character will be whether it is tied in some way to a particular normative moral orientation. (5) In addition to dividing on the moral/nonmoral description, those that are moral in this category sense are open to either positive or negative evaluation from a given moral point of view. (This latter point allows us to speak of "good" or "bad" character, as well as "strong" or "weak.")

\section{Some Basic Starting Points}

For almost thirty years, Lawrence Kohlberg endeavoured to describe, to measure, and to explore the educational implications of the development of moral judgment. In doing so, he engaged in scores of empirical studies utilizing samples spread across the whole human age span and a wide variety of cultures. His empirical methodology is now very well-known world-wide, and has spawned both hundreds of studies replicating and extending his findings and a large number of critiques aiming to show that these findings are spurious in some way. His six stages of moral judgment are now as well-known to psychologists as Campbell's soup to the North American cook. But the philosophical dimensions of this theory are as important as the empirical methodology and claims. Indeed, one of the unique aspects of Kohlberg's theory of moral development, compared to the rest of mainstream North American social psychology, is the way that it explicitly integrates into an empirical concern certain understandings of persons and morality which would normally be solidly located on the philosophical side of the renowned gap between psychology and philosophy. As I have argued elsewhere, ${ }^{8}$ it is this combination of kinds of claims that has led to one of Kohlberg's 
more radical, but still mostly nisunderstood, theoretical claims about the "naturalistic fallacy." Although individually these philosophical starting points of Kohlberg's theory are undoubtedly well-known, a synthesis of them is warranted here for two reasons: first, because any thorough dialogue with alternative approaches to moral experience and growth will in the end revolve around these starting points, and second, because my eventual claims about the kind of character that fits stage six are necessarily tied to these starting assumptions that ground and frame developmental theory.

The following consists of what seem to me some of the most basic starting points of Kohlberg's theory:

(1) At the most foundational level is an assumption about the human self which is probably drawn from Mead. The assumption is that the psychological self--the sense of "myself" that we all have--is a social construct. "Self" and "other" are not metaphysical entities, each standing alone, totally independent. They are, rather correlative categories, both conceptually and developmentally. One's own self and the self's needs can only be delineated in reference to an awareness of others-as-selves and their needs, and vice versa. We give moral weight to these divisions via our notion of personhood which recognizes that the welfare of one self can be both benefited and harmed by others.

(2) The second assumption is that the institution of morality is a mode of regulating the interaction of such persons with regard to both manners of possible effect on each other. Kohlberg shared with many contemporary philosophers an understanding of morality as a kind of social tool and an understanding of the twin functions this tool is meant to serve. For example, Thomas Nagel has articulated this assumption quite neatly: "The central problem of ethics [is] how the lives, interests, and welfare of others make claims on us and how these claims, of various forms, are to be reconciled with the aim of living our own lives." 9 Moral evaluations are then judgments of the appropriateness of some act or pattern of action that might be performed by an (or any) person insofar as it affects the interests of another person or persons. The type of effect can be either in terms of their benefiting from another's help or care, or in terms of their claims to forbearance of another's infringement on their projects or autonomy, or some combination of these two directions of influence. In short, Kohlberg's psychological theory and findings must always be understood in the context of a particular view of morality; the "moral" in "moral development" has specific and explicitly recognized conceptual boundaries. To put all this in Kohlberg's own lerms, let me quote from his response chapter in the recent collection, Lawrence Kohlberg: Consensus and Controversy: 
... Some philosophic definition of the moral domain is required as a starting point for psychological or empirical study of moral development or morality becomes synonymous with all valuing. Since my thesis I have defined developing morality as involving "a moral point of view" including not only Kant's or Hare's prescriptivity, universalizability and over-ridingness and its implication of judging and acting on principles, but also including impartiality or considering the good of everyone alike and reversibility, which is not quite the same as universalizability. The "moral point of view" is somewhat broader than a concern for distributive, commutative and restorative justice, since it can centre on an attitude or principle of beneficence in situations without conflicting claims between two or more others and only involving the self and one other $\ldots . .10$

(3) A third assumption consists of an integration of the first two; i.e., it returns to a view of the person, but now in the context of the interaction of persons and their construction of the mode of mutual regulation called morality. The assumption is that part of what it means to be a person is the effort to be a moral person. Kohlberg rarely acknowledged this assumption in so many words, perhaps because it was so central to his own understanding of his project of identifying stages of moral judgment that he assumed it would be obvious to anyone else. But unfortunately it has remained too much in the background of the common understanding of his theory, with the result, I would suggest, that much of the interpersonal relational flavour of the theory has been missed by both critics and supporters alike. However, it was acknowledged quite explicitly by Kohlberg in a recent reply to some critics. Arguing that he has always avoided any "emotivist" view of the stages (by which he means an interpretation of the stages in terms of different motives), Kohlberg points out that, instead,

... I have claimed that in some sense there is a primary motivation "to do the right thing" in the socio-moral world as Piaget assumed a primary adaptation [of] 'truth' motivation for the infant and child's actions toward the physical world. 11

This may be a slightly unfortunate way of putting it because the notion of doing the right thing overshadows the notion of figuring out what is the right thing to do and tends to eclipse the conceptual point that the latter is necessarily part of "doing the right thing." 
Moreover, I am not sure what kind of action Kohlberg had in mind here, nor the extent to which he wanted to build a behavioural disposition into his conception of the person at this level. However, I think that at the very least--and this is all we need--he is claiming that his conception of the human person includes a natural disposition to actively seek a balance between (to use Nagel's words again) "how the lives, interests, and welfare of others make claims on us and how these claims, of various forms, are to be reconciled with the aim of living our own lives." The self of our first assumption is not just delineated in terms of the other (and vice versa) but also in terms of its active attempt to understand, respond to, and balance the perceived needs of both the self and others.

(4) A fourth step in these starting points of Kohlberg's theory pulls these existing strands even tighter together: the intentionality of morality is assumed and integrated with the developmental nature of the moral person. It has already been noted how Kohlberg shared with many contemporary philosophers a view of morality as a social tool constructed by humans to regulate certain aspects of their interaction. However, to say this is to take an external view of that function, to stand outside the institution of morality and make a descriptive claim about it. But such an external perspective can never provide more than a partial picture of that institution. The reason for this is that a moral act is an intentional act that is tied intrinsically to a particular kind of reason. It is not just a piece of behaviour which, observed from the outside, can be seen to serve a certain social function; instead, it must also be viewed from the inside, from the point of view of the moral agent. And from this perspective, a moral act is something which a person does, in order to accomplish some goal or purpose, which is judged to be good and/or obligatory by that person, according to that person's understanding of how the needs of self and other can best be balanced. Charles Bailey has made this point recently: "Out of the context of reflection and judgment pieces of behaviour are neither moral nor immoral but mere happenings; part of the natural world but not of the world of morality" (199). 12 Kohlberg often identifies this part of the assumption by referring to his "formalist" meta-ethical position which guides his empirical enquiries. For example:

For the 'formalist' meta-ethical philosophic position I hold, a necessary part of a moral action is guidance or justification by a moral reason, i.e., by a judgment of rational and autonomous obligation. 13

In addition, the second part of this fourth assumption is that the particular form which this "judgment of rational autonomous 
obligation" may take in any instance of intentional moral behaviour (whether engaged in or contemplated) will depend, at least in part, on the understanding of the notions of moral persons and their interrelation which is currently operative for the person making the judgment. That is, within this theory moral agents are seen as meaning-makers. They do not more or less successfully just passively absorb and reflect some fixed moral reality which is a priori and independent of their efforts; instead, they are continually engaged in the activity of constructing that reality through their efforts to "make sense" of their relations to others which are perceived as like the self but not the self. Depending on the experiences the person has had, not the least of which are role-taking opportunities, different coherent patterns of understanding this aspect of the social environment emerge and function as a framework for communication and interaction with other persons. These are the stages of moral judgment which form the core of Kohlberg's empirical theory.

(5) Finally, a fifth assumption elaborates the interpersonal nature of this constructive endeavour. It is true that the individual person strives to "make sense" of his/her moral relationships to others and then uses this understanding in the framing of intentional moral acts. But this further point consists of the recognition that the only meaning that can make sense, given the area of concern as defined, is shared meaning. This is now the full sense of the notion of morality as a social tool: in short, it is a mode of interpreting human experience which is meaningful only because it is a shared construction by more than one person. Moral concepts (of this sort), e.g., trust, equality, care, respect, are the meaning-tools we have that are our pre-eminent expressions of our recognition of the lived reality of others and our claim on their recognition of ours. Moreover, the use of these concepts in the formulation of reasons and rules meant to guide moral action is also necessarily a matter of shared construction. As we have seen from previous assumptions, morality according to this view is our way of balancing the claims arising from the interaction of lives, interests, and welfare. But these very claims are not given, not static; they emerge from the real interaction of different, but connected persons. And they always, necessarily have points of view built into them. Thus, reasons for action aimed at balance are always essentially contestable and can only be aimed at mutual acceptance. As Kohlberg puts this point, "... the function of moral reasoning, judgment and argumentation is to reach agreement where claims or interests conflict, most especially where the conflict is between two or more persons ...."14. In short, moral persons "are not thought of as independent, isolated 'rule followers,' with greater or lesser direct access to moral truth, but rather as rule-followers-inrelation who must construct and continually reconstruct through 
public dialogue the perspective from which rules governing their interaction have validity." 15

As I have already argued, it is this kind of assumption which describes Kohlberg's theory of moral development as much as, or more than, the empirical claims which are perhaps more commonly known. It is these assumptions which, quite literally, give the empirical claims meaning; i.e., they allow us to interpret what it means to say that people tend to solve moral problems by use of different stages of moral reasoning and tend to go through these stages in a sequential, invariant order, from one to six. There are probably other such general assumptions which we would need to explicate if we were after a comprehensive view of Kohlberg's theory. However, 1 would argue that any such comprehensive view would have to include, and be anchored in, the ones I just articulated. Moreover, I believe they are all we need for my purposes in this paper, namely, to explore the character of development in the way I have suggested.

\section{Some Ways of Misinterpreting Stage Six (And the Character of those Misinterpretations)}

Given an acceptance of these basic assumptions as philosophical starting points of Kohlberg's theory, I think it is easier to see why some common interpretations of stage six are surely mistakes, mistakes which have character implications that are thus avoidable. In identifying some of these mistakes, 1 intend not only to correct them but also to illuminate the path towards greater understanding of the character traits intrinsic to (or at least required by) Kohlberg's theory.

Probably at the root of the interpretation $I$ want to deflect is a narrow view of reason which is exaggerated to the point of caricature by the time stage six is considered. Kohlberg's theory is often characterized as describing increasingly adequate stages of moral reasoning. If the lower stages of reasoning are to be regarded as lower, it must be because they have so little reasoning in them. As you climb the sequence, you get more reasoning. And this increases until you reach stage six where you have "pure reason." Stage six is thought to be nothing but reason. But then, a critic will say, what an inhumane notion of moral maturity! Instead of of moral goodness described in human terms of flesh and blood, aspirations and their perversion, affect, will, and strength of character, we get a cold, bloodless, calculating machine, or at least a rigid template for making calculations.

Raising, as it does, large issues about theories of rationality and the emotions, and the relationship between the two, I cannot hope to deal completely with this problem here. However, I believe it is suf- 
ficient to avoid this absurd conclusion to point out that it rests on a confusion of the conceptual point about what constitutes a moral act, with the normative criterion that must be appealed to for any "developmental" claim with regard to the increasing adequacy of the stages. As we have already seen, one of Kohlberg's starting points is the intentionality of morality, which simply means that (to use Bailey's words again) "to be viewed in a moral dimension at all, a situation and its attendant feelings must always be rationally appraised."16 What counts as appropriate and thorough rational appraisal cannot come from this conceptual point alone. Magnifying the rational side of "rational appraisal" to the image of "cold and calculating" rests on exactly this confusion. That image of stage six begins to lose its grip on us when we realize it depends on this confusion.

It loses even more when we realize that to say that something is conceptually tied to rational appraisal is simply to say, at the most basic level, that it is something about which one can/should "stop and think," and without this element (at least in principle) one is engaged in something else--perhaps anxiety reduction, instead of morality. Finally, it begins to look downright silly when we realize that, contrary to the image of a calculating machine which can only manipulate a priori assumptions, any developed form of rational appraisal such as stage six will necessarily be imbued with strong powers of imagination. What I mean here can perhaps best be expressed through the words of the novelist Robertson Davies (via the Oxford lawyer, Pargetter, speaking to Davey Staunton):

When I say imagination I mean capacity to see all sides of a subject and weight all possibilities; I don't mean fantasy and poetry and moonshine; imagination is a good horse to carry you over the ground, not a flying carpet to set you free from probability. 17

In this case, the "ground" that needs to be covered has already been formally staked out in the other starting assumptions of Kohlberg's theory identified above. Seeing all sides of a subject and weighting all possibilities is clearly required in any mature form of our constructive activity of "making sense" of our social environment--and especially the conflicts within it arising from the different points of view inherent in different persons--in service of balancing the claims arising from the lives, interests, and welfare of both others and self. To reduce this to any narrow sense of calculative reason is simply to miss the rich theoretical context within which the stages exist.

A second characteristic of this line of interpretation which I 
want to expose and reject probably originates from a shallow understanding of the notion of a moral principle, which, according to the quoted short description of stage six, will be a mainstay of the appropriate rational appraisal. According to this mistaken view, principles are abstract moral rules, "out there," external to though discoverable by human consciousness. They are seen as rigid, inflexible stopping points to our moral deliberation and justification. They are thought to be sufficient to dictate answers to concrete moral problems, with the additional power to determine unique answers in all cases. They are, supposedly, by virtue of being blind to context and situational particularities, the way in which we establish consistency in our moral response, even when (especially when?) that consistency is at the expense of perceived complexity and remaining problems. When the notion of moral principles is interpreted in this rigid way, the mind that must find them congenial is to a large extent closed (especially in complex moral conflictual situations of the sort stage six is supposed to be able to handle). Further, the character that is at least suggested approaches the caricature of a martinet "Goody Two-Shoes." 18

Again, I think an adequate response to this view can be made without elaborating a thorough analysis of the nature of role of moral principles in moral deliberation and/or justification. What we need to see is that there is a kind of consistency which the notion of being principled picks out, but it is not the kind identified by the view at hand; and it can be seen as a kind of virtue, though for diametrically the opposite reason from what this mistaken view suggests. In short, we need to keep in mind that principles are not directly related to particular concrete acts as are moral rules (e.g., as in "Do not steal"), but rather serve to compare and evaluate different acts falling under different, often conflicting rules. They are, in Dewey's words, "a method and scheme for judging"19 which exist because we construct them. They are not, then, final stopping points of deliberation or justification, but flexible attempts to integrate solutions to difficult problems into coherent patterns. A sense of consistency is part of the principled picture, but it is consistency in consideration of relevant perspectives, not sameness of answer. When this characteristic of consistency is extended from a logical property of principles to an aspect of personhood, it must be properly qualified by the quality of open-mindedness. Principled judgment is dynamic, not static; it is not evidence of a closed mind achieving consistency by ignoring things, but rather the way in which we strive to keep our minds open in order to seek consistency of evaluation.

A third commonly implied, but I think mistaken, characteristic of principled moral judgment could perhaps be developed as part of the second just discussed; however, I believe it is enough of an exten- 
sion of this mistaken view of principles, and of sufficient importance, to warrant separate treatment. What $I$ have in mind here is what happens when this mistaken view of the logical and functional properties of principles is extended to more psychological process claims about how principles are thought of as being used in moral judgment. Here we run into the common notion of a "principled person" as one who is in a sense inflexible in the context of adherence to chosen principles, as one who does not countenance doubt or slippage when it is a case of, or opportunity for, "sticking to one's principles." This is the sense of principle-in-use which is captured by the colloquial notions of "standing on principles" and not budging from a claim with regard to what one sees as "the principle of the matter." There is, of course, an important truth in this view. This truth is that there is a universalizability requirement built right into our notion of 'principle' and the particularly stringent test case for meeting this requirement with regard to some principle that one is claiming to use is when dropping the principle would somehow favour one's own interests, but one still maintains it.

However, this truth is only part of the whole picture and consists of a serious misrepresentation when taken as the whole picture. What we need to balance it and complete the picture of how principles function might be captured by the notion of a sense of irony. That is, it is the flexible perspective on judging which principled consideration can provide that gives one room to acknowledge and appreciate incongruities between rule-dictated expectations and what one senses ought to be the case. It is this openness to irony in the face of moral imperatives that provides the superior adaptability of principled judgment and is a necessary antidote to blind persistence of commitment. It is, in short, an essential aspect of attitude for a view that, as we have seen earlier, conceives of moral principles as interpersonal constructions of meaning.

This line of argument could be continued for some time, all of it suggesting ways in which we need to be careful in how we conceptualize principled moral judgment. However, 1 think we already have enough to facilitate a more direct analysis of what might be at issue between the two views. It should be remembered that my purpose in exposing and correcting these mistaken interpretations is ultimately to approach the question of what kind of character best fits our understanding of the stage six form of moral judgment. What I have done so far is to synthesize one common view which I think takes us in the wrong direction in answering this question, and to suggest what needs to be added in order to correct the view. To summarize, I have noted how the mistaken view tries to paint a picture of a person who is "purely rational," disposed simply to casuistically manipulate known factors, who seeks a sense of consistency through appeal to external abstract rules which simply lay down answers for 
us, and who has a strong sense of stick-to-itive-ness whenever a situation calls a rule into question. I have sought to repaint this picture by noting how appropriate use of reason requires a strong, active imagination, how principles really require consistency of perspectiveseeking which entails open-mindedness, and how proper use of principles promotes ironic adaptability more than inflexibility.

\section{The Stage Six Moral Point of View, Objectively Speaking}

Now these characteristics of persons, as extrapolated from the two different interpretations of stage six, are aspects of personality which could at least in some contexts be considered aspects of character. But, as they stand so far, they are what we would have to call non-moral character traits; neither interpretation is as yet a picture of moral character, because all of the components of both interpretations can be manifested in clearly non-moral contexts. As noted above, such traits can only be described as moral character traits when they are manifested in the service of a normative moral orientation. The question $I$ want to turn to now is: what are the moral orientations which could convert these two pictures into pictures of moral character? I want to show how only the second of the two pictures will be congruent with, and can be seen as traits in the service of, the particular moral point of view expressed by stage six. Further, this point of view can be operationally expressed in such a way as to uncover and illuminate heretofore unsuspected dimensions of character which would seem to be required by stage six.

To answer the question of what moral point of view could utilize the two pictures, we have to return to the "starting points" of Kohlberg's theory which I articulated at the outset of this paper. I have pointed out that Kohlberg's theory starts from a view of morality as a social construction aimed at mutually acceptable regulation of the interaction of persons in terms of how they might benefit from, and avoid harm in, that interaction. Or, as Nagel puts it, it is the institution which organizes our attempts to solve the problem of "how the lives, interests, and welfare of others make claims on us and how these claims, of various forms, are to be reconciled with the aim of living our own lives." 20 Since the whole point of morality, according to this view, is the achievement of this regulation in some sort of reasonable balance, it cannot be done solely from within the point of view of any particular person's life, interest, and welfare. Instead, it necessitates the construction of a perspective which is external to--or "out there"--relative to any and all such particular points of view, while at the same time maintaining an appreciation of exactly that particularity in its every instance. But note that 
what I have just said identifies the concept of objectivity as intrinsically connected to the moral project so understood; objectivity is exactly that characteristic of our judgment that somehow is congruent with something "out there" such that error in judgment can be picked out with some confidence and with inter-subjective recognition. The "moral point of view" which Kohlberg often refers to (as quoted earlier) is then that point of view within human judgment about acts involving the claims arising from the lives, interests, and welfare of more than one person which lays claim to objectivity. What is needed is a better understanding of how a particular view of objectivity shapes the moral point of view at the heart of Kohlberg's theory.

First of all, we need to see that an inadequate view of 'objectivity permeates the mistaken interpretation of stage six which I have been at pains to avoid. In brief, I think that the characteristics which I identified as part of the common, but mistaken, interpretation could be seen as moral character traits only by their being conjoined with the interpretation of objectivity inherent in what Kohlberg has described as a "conventional" understanding of morality. On this interpretation what suffices to establish objectivity about moral claims is not any direct reference to the lives, interests, and welfare of persons involved, but rather an appeal to whatever set of abstract role expectations and/or rules of conduct which constitutes a particular social system. It is the existence (or positing of the existence) of these role expectations and systemic rules which provides the "out there" perspective relative to the claims inherent within any particular person's point of view. And it is in reference to this conception of morality that the person with a casuistical sense of reason, seeking consistency via clear appeal to rigid rules and simple solutions, not wavering from the task of maintaining allegiance to the rule, who is thought to have moral character.

Now if this were the interpretation of objectivity inherent in Kohlberg's ideal of stage six principled morality, then we would have good reason to express concern, along with the critics, about the concomitant picture of character. But I would argue that this view of objectivity is at fault for leaving the subjectivity of persons--both that of the moral judge and that of the others whose claims need considering--out of the picture, in a way that cannot be done in stage six. It is a kind of reification of the "out there" that is more appropriately identified, as Deutscher does, as "objectivism:"

Objectivism is the view that would have us forget that it is a view; the objectivist is a subject who would forget and have others forget that he is a subject. There is only what is viewed; the viewing of it is passed over (29). 21 
When objectivity is understood in this way, it spawns a legitimate complaint that the particularities of real persons and their interaction are eclipsed and seen as secondary in importance to the "objectivity" of impersonal and abstract "principles." That this complaint cannot be justifiably directed at Kohlberg can be seen by combining a fuller understanding of the normative core of stage six with the more dynamic sense of objectivity which is required by it. In the process of doing this, we will also illuminate the essential dimensions of the character of stage six.

First, as I have argued elsewhere 22 , the normative core of Kohlberg's moral orientation is properly located in the notion of respect for persons, not in any narrow view of "justice." It is true that justice has usually been explicitly identified as his focus of attention and, in a few places, he has even seemed to equate all of morality with justice. However, this has always turned out to be a very broad notion of justice, one grounded in and seeking to express (in his words) "respect for the dignity of human beings as individual persons." 23 Given the conception of persons articulated earlier as one of Kohlberg's basic starting points--as relationally-defined social selves who have claims on each other both in terms of needing positive help in fulfilling interests and in terms of requesting equal consideration of those interests as an expression of autonomy--respect for persons does necessitate justice as one dimension. But it is important to keep in mind that this dimension is always contextualized by a more general and diffuse dimension of furthering the other's welfare as one's own, i.e. of benevolence.

An active, reflexive dealing with these different dimensions of moral experience is now quite clearly articulated by Kohlberg and others as a necessary aspect of our understanding of stage six:

From a Stage 6 standpoint, the autonomous moral actor has to consciously co-ordinate the two attitudes of justice and benevolence in dealing with real moral problems in order to maintain respect for persons. The way of regarding the other which we are calling benevolence views the other and human interaction through the lens of intending to promote good and prevent harm to the other. It is an attitude which presupposes and expresses one's identification and empathic connection with others... Thus, as a mode of interaction between self and others which manifests a Stage 6 conception of respect for persons, benevolence is logically and psychologically prior to what we are calling justice. On the other hand, justice views the other and human interaction through the lens of intending to adjudicate interests, that is, of intending to resolve conflicts of 
differing and incompatible claims among individuals. Given this adjudicatory lens, justice presupposes a momentary separation of individual wills and cognitively organizes this separation in the service of achieving a fair adjudication through a recognition of equality and reciprocal roletaking. Thus, these two attitudes of benevolence and justice may be experienced in potential tension with each other... We wish to emphasize that although these two attitudes are in tension with each other, they are at the same time mutually supportive and co-ordinated within a Stage 6 conception of respect for persons. This coordination can be summarized thus: benevolence constrains the momentary concern for justice to remain consistent with the promotion of good for all, while justice constrains benevolence not to be inconsistent with promoting respect for the rights of individuals conceived as autonomous agents. In other words, the aim of the autonomous Stage 6 moral agent is to seek resolution of moral problems in such a way that promoting good for some does not fail to respect the rights of others, and respecting the rights of individuals does not fail to seek promotion of the best for all. As Baier has succinctly put it, the moral point of view must evaluate "for the good of everyone alike." We think this co-ordination is what makes the golden rule so compelling and timeless. That is, in its positive interpretation, "Do unto others as you would have them do unto you," it expresses the attitude of benevolence, as elaborated in the Christian maxim of "Love thy neighbour as thyself." On the other hand, in its proscriptive interpretation, "Do not do unto others as you would not wish others to do unto you," it expresses the attitude of justice as respecting and not interfering with the rights and autonomy of others. 24

It is this understanding of respect for persons which must be kept in mind in any analysis of the normative orientation underlying Kohlberg's conception of moral maturity, and thus his whole theory of moral development. Clearly, a thorough exposition of the claims made with regard to this orientation, and particularly how it gets operationalized in terms of psychological processes, is beyond the scope of this paper. 25 However, we already have enough here for us to proceed with the question at hand. The essential point is that the disposition to treat others with respect in this general sense will necessarily be at the core of the view of moral character congruent with stage six. 
Although it is often overlooked, the first point is quite straightforward: both "dimensions" of moral experience--one might even say "poles"--found within the aim of maintaining respect for persons can be expressed in character terms. The attitudes of benevolence and justice are "ways of regarding" others in view of the claims their lives, interests, and welfare make on us. Each of these ways of regarding others can be expressed in terms of a principle of action resulting in analysis of moral problems from the perspective of principles of justice and beneficence. But, in addition, both can also find expression as a dispositional state of being qua person. That is, both benevolence and justice can be understood as fundamental moral character traits. Indeed, Frankena 26 argues, and I agree, that these two are the only instances of what he calls "cardinal virtues." What he means by this is that "they cannot be derived from one another and all other moral virtues can be derived from or shown to be forms of them." 27 In short, a character which is formed primarily in terms of the cardinal virtues of benevolence and justice is clearly congruent with stage six.

But there is another piece of the picture which can be pulled out of the way respect for persons is seen as organizing benevolence and justice in stage six. Frankena also recognizes the potential tension or conflict between these two dimensions, but he does not actively deal with it beyond expressing the "hope" that they "are in some sense ultimately consistent." (53) What we want to say about stage six, however, is that it is a form of moral judgment which entails the active seeking of the co-ordination of the attitudes of benevolence and justice via the attitudes of respect for persons. Stage six does not just view some situations as matters of benevolence and others as matters of justice; rather, it realizes that approaching a situation with either concern may have implications for the other concern. And it is the placing of oneself within the process of co-ordinating the different pulls of moral action which the active sense of respecting persons captures. Further, what this means, in terms of our central question of this paper, is that there must also be aspects of character which are congruent with this attitude of respectful seeking of co-ordination of moral response, in an enduring expression of moral personhood.

\section{Objectivity Recycled and the Character to Make It Work}

It is here that we have to return to the issue of the nature of objectivity in morality raised earlier. I will argue that this requirement of conscious co-ordination of benevolence and justice is inherently tied to a particular, dynamic understanding of objectivity in morality. In the end, l want to show that it is through a view of 
objectivity in moral judgment as "essentially performative" that the centrality of persons to stage six is firmly established and the full nature of respect for persons is operationally captured. Through this analysis, we will also see how certain further character traits are not superfluous additions but, rather, necessary ingredients of a stage six sense of respect for persons.

I have already noted, very roughly, how the concept of objectivity links the possibility of error in judgment with both some kind of external perspective and the aim of inter-subjective agreement. And I have also rejected the particular interpretation of this linkage, found in the common, mistaken view of principled morality, in terms of a shared acceptance of a set of definitive, abstract, inflexible moral rules from which any person can derive "the correct" answers to moral questions. I labelled this view "objectivism" because it consists of a reification of moral truth such that it is impossible to see the subjective activity of persons constructing that perspective. In contrast, we should be looking for a much more constructive understanding of moral truth and error. A number of contemporary philosophers of various persuasions have argued for this view. 28 What we need is some account of how objectivity can be understood so that it provides an external perspective for identifying error, in such a way that does not lead us into objectivism. The essentials of such an account are as follows. First, I think objectivity needs to be seen as identifying a certain kind of perspective on judgment, when "judgment" is taken in its activity sense, as something that one does or performs. Second, this perspective can be loosely expressed as a kind of detaching or decentering. That is, the objective perspective is in the direction of recognizing, and seeking some kind of reflexive or "reconsiderative" distance on, some aspects of our present understandings or claims. The essential functional point about objectivity, then, is that it consists of whatever kind of detaching or decentering that best facilitates reflexivity on our own claims .. and in such a way as to keep open the possibility of the continuation of this reflexive detaching. I think Nagel has captured all the constituent parts of this understanding very precisely in his general interpretation of objectivity.

Objectivity is a method of understanding. It is belief and attitudes that are objective in the primary sense. Only derivatively do we call objective the truths that can be arrived at in this way. To acquire a more objective understanding of some aspect of life or the world, we step back from our initial view of it and form a new conception which has that view and its relation to the world as its object. In other words, we place ourselves in the world 
that is to be understood. The old view then comes to be regarded as an appearance, more subjective than the new view, and correctable or confirmable, by reference to it. The process can be repeated, yielding a still more objective conception. 29

There are several points of this interpretation that $I$ need to emphasize before exploring what it means in the context of the moral point of view of stage six. The first point that is crucial to keep in mind is that objectivity is primarily connected to inquiry, not answers. Thus in the passage just quoted, Nagel identifies objectivity as a "method of understanding" and notes that only derivatively do we call objective the truths that can be arrived at in this way. What we should be focusing on is not some kind of results or products of understanding, for example, as determined by rigid rules deductively applied, but rather the way or manner in which they are pursued. (In the context of a concern about objectivity in moral judgment, it is important to keep in mind that the term "judgment" is often ambiguous: it can refer either to a way or mode of making decisions--a process--or to the result of particular efforts at decision making-a product. The point here is that the focus of our attention, when we are concerned about objectivity, is properly judgmentas-process, rather than judgment-as-product). Active language is the appropriate mode of description, as is accurately reflected in Nagel's further description in this passage: "To acquire" it "we step back," "place ourselves," in a "process" that "can be repeated."

The second point that I want to emphasize here is a corollary of understanding objectivity as a method of understanding: interpreted in this way, objectivity must always be tied, in some way, to an intentional subject. It is something that one does, not something that happens. The reflexivity that properly modifies the detaching aim of objective thinking can exist only if there is a human subject still within the thinking to refer back to, a fact which must be held consciously even when in tension with that direction. As Deutscher says, "...Objectivity is a form, a style, an employment of our subjectivity...not its antithesis.... We can speak of a 'point of view' and say that objectivity is possible only within a point of view and is thus a quality of one's subjectivity." 30 Only an intentional, thinking subject can be said to have a point of view, and objectivity is the aiming at a particular kind of point of view--one which includes some aspect of that subject and/or its thinking as part of its object.

The final point important for my purposes here consists of a recognition of the necessarily paradoxical flavour of this conception. As Nagel so clearly sees, the puzzle is that for any pursuit of objectivity,

2(2), Spring, 1989 
its aim is naturally described in terms that, taken literally, are unintelligible: we must get outside of ourselves, and view the world from nowhere within it. Since it is impossible to leave one's own point of view behind entirely without ceasing to exist, the metaphor of getting outside ourselves must have another meaning. We are to rely less and less on certain individual aspects of our point of view, and more and more on something else, less individual, which is also part of us....

Since we can't literally escape ourselves, any improvement in our beliefs has to result from some kind of selftransformation. And the thing we can do which comes closest to getting outside ourselves is to form a detached idea of the world that includes us, and includes our possession of that conception as part of what it enables us to understand about ourselves. We are then outside ourselves in the sense that we appear inside a conception of the world that we ourselves possess, but that is not tied to our particular point of view. 31

What affect does this notion of objectivity (as opposed to the one 1 have suggested is inadequate), have on our understanding of the stage six moral point of view? I think this conception of objectivity is what locates persons at the centre of the stage six notion of principled moral judgment, both as intentional moral agents and as objects and subjects of respect. To see this clearly, we must again refer back to Kohlberg's philosophical starting points which 1 treated briefly at the beginning of this paper. It will be remembered that the conception of morality underlying Kohlberg's theory is grounded in a view of social selves correlatively defined and then is elaborated as persons trying to "make sense" of their interaction, through their shared endeavour of striving to balance the claims that the lives, interests, and welfare of each make on each other. Then when we take this understanding as the arena within which objectivity, in the sense just articulated, is understood, what we immediately see more clearly is that the plural form of Nagel's discussion of the basic metaphor of objectivity--"we must get outside ourselves"--cannot always be interpreted as a "royal we," or as referring to all of us, but individually and separately. On the contrary, within the moral point of view of stage six the "we" that must "get outside ourselves" is truly and necessarily plural. 32 Objectivity in morality is a method of understanding which simply cannot, in the end, be engaged by one person alone. On the contrary, it entails two people (or more) aiming at reflexive detaching or decentering together, with respect to each other 
and self, often at the same time. It is in regard to this mutual effort, in the context of claims of both benevolence and justice arising from the lived reality of each (or all), that the earlier noted characteristics of imagination, open-mindedness, and a sense of irony can be seen to be subordinate moral character traits.

However, there are also other, more central aspects of character which only now become clearly visible. The first of these puts to rest, once and for all, the criticism of stage six as cold and impersonal: an essential aspect of moral objectivity must be the enduring expression and presentation of one's self to the other as sympathetic! Mutual decentering hinges directly on this disposition to try to see and feel as the other sees and feels within his/her lived context and understanding of that context. As Frankena puts it, "we must somehow attain and develop an ability to be aware of others as persons, as important to themselves as we are to ourselves, and to have a lively and sympathetic representation in imagination of their interests and of the effects of our actions on their lives." 33 He points out how the need for this has been stressed by Josiah Royce and William James:

Both men point out how we usually go our own busy and self-concerned ways, with only an external awareness of the presence of others, much as if they were things, and without any realization of their inner and peculiar worlds of personal experience; and both emphasize the need and the possibility of a 'higher vision of inner significance' which pierces this 'certain blindness in human beings' and enables us to realize the existence of others in a wholly different way, as we do our own. ${ }^{34}$

As James says, "we ought, all of us, to realize each other in this intense, pathetic, and important way." 35 What it requires, as a character expression of moral objectivity, is the enduring disposition to seek an integration of one's understanding and affective appreciation of what the other is really like and what the other is really feeling, as much as possible independent from both one's own phenomenological situation and one's pre-conceived understanding and appreciation of the other.

Then, in addition to resting on this kind of basic, mutual sympathetic connection, the kind of objectivity which a stage six respect for persons seeks also entails a mutual reflexivity on understandings and claims. And this requirement has additional, distinct character implications. To see this, we must first recall that objectivity not only requires a kind of detaching or decentering (which we have just seen to involve sympathy in the case of moral judgment), but also 
this is to be sought in such a way as to facilitate reflexive reconsideration of some present understanding or claim. But, as we have also seen, in morality there is by definition a plurality of points of view from which such understandings and claims arise. Thus, there is also a plurality of both subjects and objects of such reflexivity required by objectivity. Stage six moral objectivity is expressive of respect for persons through its necessitating a disposition of persons to engage others performatively with regard to moral interactions, both those involving benevolence and those involving justice--and especially those requiring an integration of the two attitudes. Quite simply, what this performative engagement requires is the dispositional realization that all individual understandings of either benevolence or justice claims are potentially (and likely) limited by the particular subjective point of view of that individual and that offering them to others with the expectation of their agreement or disagreement, supported by their counter-understanding from their points of view, is a necessary condition of determining the best understanding. In short, complete reflexivity in matters of moral understandings can only be achieved through dialogue.

The additional character implications of this full picture are now apparent. First, as we saw earlier, all of the traditional subordinate character traits, such as courage, patience, loyalty, etc., should be thought of as derivatives of (or sometimes expressions of) the two cardinal virtues of benevolence and justice.. That is, they can be considered moral character traits only insofar as they are contextualized by the moral point of view framed by benevolence and justice. The connection that is most commonly seen here is that sometimes in order to act benevolently or justly one does need to be courageous, patient, loyal, etc. Undoubtedly this is true. But what our understanding of objectivity adds to this picture is that, in addition and perhaps at a more fundamental level, these other traits are matters of moral character insofar as they make possible and facilitate our performative engagement of each other about what constitutes the benevolent or just act.

A more important point is that we can now identify two additional higher level character traits which seem to be required by our understanding of how a particular view of objectivity interacts with the normative dimensions of stage six. Both of these are on a par with the manifestation of sympathetic connection discussed earlier. The first is, perhaps surprisingly in the context of the self-righteous flavour often attributed to stage six, humility. One's performative engagement of the other involves making claims of validity for one's current understandings, but it simply cannot function without the conscious realization, expressed in both attitude and behaviour, that "I could be wrong" about those understandings. Only through being humble can a person allow room for other persons and their alter- 
native understandings to be heard and to be considered reflexively by all. Whereas being sympathetic, in the sense outlined above, provides the substantive concerns around which moral judgment revolves--and thus objectivity in moral judgment must accommodate--being humble with regard to the validity of one's moral claims and the appropriateness of one's moral actions is required to show respect to other persons' sympathetic interpretations and subsequent claims to objectivity in judgment and action.

The other high level character trait which can also now be seen as required by an operative notion of stage six principled morality consists of a dispositional expression of a sense of responsibility for maintaining the conditions of dialogue through which performative engagement can function, and thus objectivity can be sought. As being sympathetic is needed for identifying moral concerns, and being humble is needed to facilitate their common interpretation, being responsible undergirds the whole activity through time. There are at least two senses in which responsibility is called for. On the one hand, one needs to be responsible in the sense of being ready and willing to respond to the other. It is not enough merely to be sympathetic and humble; unless one is also prepared and inclined to respond to others' differing perspectives and judgments, one is simply not respecting them as equals in the performative engagement. On the other hand, and in conjunction with this first sense, one also needs to be responsible in the sense of doing everything one can to ensure that the material pre-conditions of dialogue are in place and maintained adequately. Here we circle back to our starting point of what morality is all about in the first place. That is, any number of different, concrete acts may be called for by this sense of responsibility--not only because one thinks them to be morally required, but also because performing them enhances the possibility that their obligatoriness and/or worthwhileness will become matters of universal inter-subjective agreement. At another level, this sense of responsibility may also call for forms of "praxis," in particular, reflective action aimed at breaking down political barriers of unequal distribution of power and economic barriers of unequal distribution of resources and wealth. Finally, also at this level, being responsible in this sense means taking the next generation seriously enough to educate them. Dialogue with the following generations is an essential aspect of the development of our shared humanity. With this concern in mind, one can then see that "moral education" is a precondition of that particular dialogue, if it is to express respect among equals. In short, moral education is an activity of responsible character, located at the intersection of respect for persons and a dynamic search for objectivity in morality. 


\section{A Concluding Note}

It is one thing to call for people of good character and the education to help them nurture it. It is quite another thing to do so in a way that goes beyond cliche to a conceptually clear, coherent picture that is theoretically grounded. Kohlberg's theory of moral development is not primarily a theory of moral character. It is a theory about how humans learn to make moral judgments in a psychologically mature way and it is at the same time a theory that is philosophically rich compared to much of the rest of North American mainstream social psychology. As a developmental theory, however, it also necessarily includes a vision of maturity that is not morally neutral. Starting with a different way of focusing its attention, such a theory will naturally see things somewhat differently from those perspectives which view the moral arena primarily in character terms. But $I$ have tried to show how an adequate understanding of the moral point of view of stage six, combined with the sense of objectivity that makes this point of view viable, goes some distance toward requiring a vision of good character in addition to a preferred form of moral judgment. It still remains to be worked out how people attain (develop?) such aspects of moral character, how educational efforts might enhance the likelihood of success in this endeavour, and how the aim might need modification to accommodate matters of additional, and perhaps competing, concern with regard to character. From the argument in this paper, however, $I$ hope it is at least clear that there is sufficient ground of common concern and an intersection of kinds of claims to make these tasks worthwhile pursuing. 


\section{Notes}

${ }^{1}$ This paper will also appear in Larry Nucci (Ed.), Moral Development and Character Education: A Dialogue (Berkeley: McCutchan, in press).

${ }^{2}$ Carol Gilligan and John Michael Murphy, Moral development in late adolescence and adulthood: the philosopher and the dilemma of the fact, in D. Kuhn (Ed.), Intellectual Development Beyond Childhood (San Francisco: Jossey-Bass, 1979), 85-89; John Michael Murphy and Carol Gilligan, Moral development in late adolescence and adulthood: a critique and reconstruction of Kohlberg's theory. Human Development, 23, 1980, 77-104; Edmund Sullivan, Kohlberg's Structuralism: A Critical Appraisal (Monograph Series, \#15) (Toronto: Ontario Institute for Studies in Education, 1977).

${ }^{3}$ William J. Bennett and Edwin J. Delattre, A moral education: some thoughts on how best to achieve it, American Educator: The Professional Journal of the American Federation of Teachers, 3(4), 1979, 6-9.

${ }^{4}$ Lawrence Kohlberg, From is to ought: how to commit the naturalistic fallacy and get away with it in the study of moral development, in Theodore Mischel (Ed.), Cognitive Development and Epistemology (New York: Academic Press, 1971), 165.

${ }^{5}$ Lawrence Kohlberg, Education for justice: A modern statement of the Platonic view, in Nancy F. and Theodore R. Sizer (Eds.), Moral Education (Cambridge: Harvard University Press, 1970), 57-83.

${ }^{6}$ Richard S. Peters, Moral development: A plea for pluralism, in T. Mischel (Ed.), Cognitive Development and Epistemology (New York: Academic Press, 1971), 303-335.

${ }^{7}$ Cornel Hamm, The concept of moral education, or in defence of the bag of virtues, School Review, 85(2), 1977, 219-228.

${ }^{8}$ Dwight Boyd, The oughts of is: Kohlberg at the interface between moral philosophy and developmental psychology, in Sohan Modgil and Celia Modgil (Eds.), Lawrence Kohlberg: Consensus and Controversy (Philadelphia: Falmer Press, 1985), 43-63.

${ }^{9}$ Thomas Nagel, The View from Nowhere (New York: Oxford University Press, 1986), 164.

${ }^{10}$ Lawrence Kohlberg, A current statement on some theoretical issues, in Sohan Modgil and Celia Modgil (Eds.), Lawrence Kohlberg: Consensus and Controversy (Philadelphia: Falmer Press, 1985), 500-1.

${ }^{11}$ lbid., 498-99.

12 Charles Bailey, Kohlberg on morality and feeling, in Sohan 
Modgil and Celia Modgil (Eds.), Lawrence Kohlberg: Consensus and Controversy (Philadelphia: Falmer Press, 1985), 197-208.

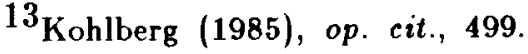

14 Ibid., 510.

${ }^{15}$ Dwight Boyd, The Rawls connection, in Brenda Munsey (Ed.), Moral Development, Moral Education, and Kohlberg: Basic Issues in Philosophy, Psychology, Religion and Education (Birmingham, Alabama: Religious Education Press, 1980), 204.

${ }^{16}$ Bailey (1985), op. cit., 203.

${ }^{17}$ Robertson Davies, The Manticore (New York: Penguin Books, 1972), 227.

18 A careful synthesis of the implied interpretation of Kohlberg against which Gilligan and Murphy (1979) and Murphy and Gilligan, (1980) (for the full citations, see footnote 2) offer their critique will adequately support the claim that this is not a case of fighting a straw-person with another straw-person.

19John Dewey, Theory of the Moral Life, 3rd ed., (New York: Holt, Rinehart and Winston, 1960), 136.

20 Nagel (1986), op. cit., 164.

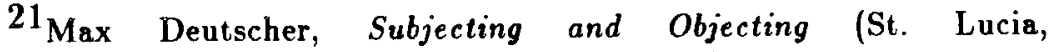
Queensland: University of Queensland Press, 1983).

22 Boyd (1980), op. cit.

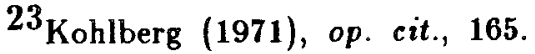

${ }^{24}$ Lawrence Kohlberg, Dwight Boyd, and Charles Levine, The return of stage 6: its principle and moral point of view, in Tom Wren (Ed.), The Moral Domain (Cambridge, Mass.: MIT Press, in press). Previously published in German as Die Wiederkehr der sechsten Stufe: Gerechtigkeit, Wohlwollen und der Standpunkt der Moral, in Wolfgang Edelstein and Gertrud Nunner-Winkler, (Eds.), Zur Bestimmung der Moral: Philosophische und Sozialwissenschaftliche Beitrage zur Moralforschung (Frankfurt am Main: Suhrkamp, 1986), 205-240. The reference in the quotation to Baier's work is to Kurt Baier's The Moral Point of View: A Rational Basis of Ethics (New York: Random House, 1965).

${ }^{25}$ For a further discussion, see Kohlberg, Boyd, and Levine (in press), op, cit.

${ }^{26}$ William Frankena, Ethics (Englewood Cliffs, New Jersey: Prentice-Hall, 1973).

27 Ibid., 64.

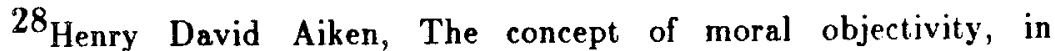
Hector-Neri Castaneda and George Nakhnikian (Eds.), Morality and 
the Language of Conduct (Detroit: Wayne State University, 1965) 69-105; J.L. Mackie, Ethics: Inventing Right and Wrong (New York: Penguin Books, 1977); and John Rawls, Kantian constructivism in moral theory, The Journal of Philosophy, 77(9), 515-572. Most recently, Thomas Nagel advances this position in The View from Nowhere (New York: Oxford University Press, 1986), even though he considers himself to be a thorough-going realist. Pointing out that "realism about values is different from realism about empirical facts," Nagel argues that the difference amounts to the fact that in the case of morality:

It is not a question of bringing the mind into correspondence with an external reality which acts causally on it, but of reordering the mind itself in accordance with the demands of its own external view of itself. (148)

29 Nagel (1986), op. cit., 4.

30 Deutscher (1983), op. cit., 41-2.

31 Nagel (1986), op. cit., 67 and 69-70.

32 The claim I am making here is my own, not Nagel's. Certainly there is a monological flavour to much of his discussion, at least when he is outlining his general conception of objectivity. It is unclear to me whether he would agree with me that this will not do for morality.

33 Frankena (1973), op. cit., 69.

34 Ibid, 69.

${ }^{35}$ Quoted in Frankena (1973), 70. 